\title{
Non-bronchial collateral arising from the right vertebral artery: a rare cause of recurrent massive haemoptysis
}

\author{
Arvind Kandoria, Kunal Mahajan, Rajesh Sharma, Vivek Rana
}

Department of Cardiology, Indira Gandhi Medical College, Shimla, Himachal Pradesh, India

\section{Correspondence to}

Dr Kunal Mahajan,

kunalmahajan442@gmail.com

Accepted 28 January 2016
CrossMark

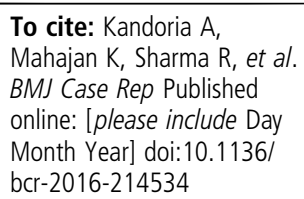

\section{DESCRIPTION}

A 48-year-old man with recurrent episodes of massive haemoptysis was referred to us for bronchial artery embolisation (BAE). He had been

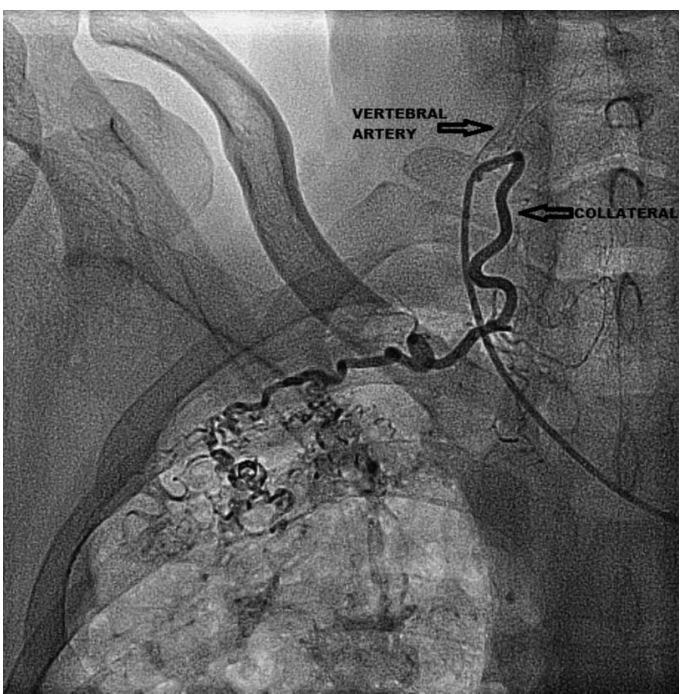

Figure 1 Selective angiogram of the right vertebral artery showing a tortuous collateral arising from its proximal part causing hypervascularity and parenchymal blush in the upper lobe of the right lung.

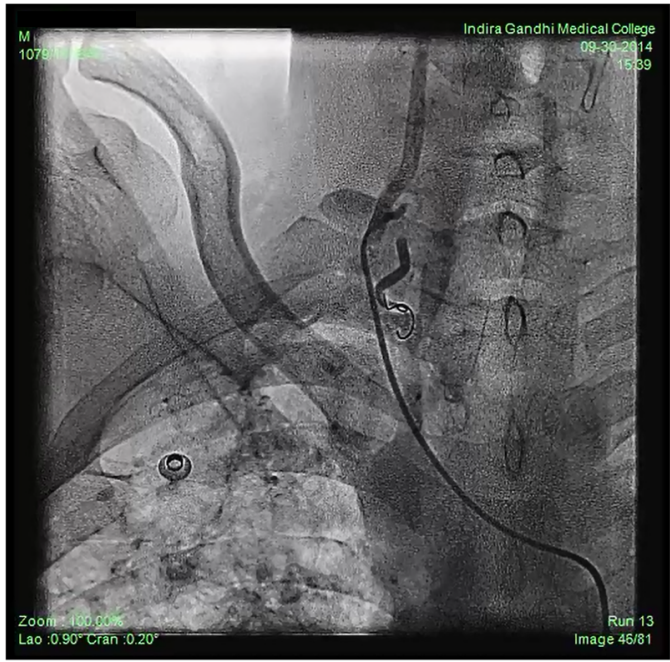

Video 1 Selective angiogram of the right vertebral artery showing a tortuous collateral arising from its proximal part causing hypervascularity and parenchymal blush in the upper lobe of the right lung. Note in the later phase of angiogram, abnormal shunting to pulmonary artery is seen. treated for pulmonary tuberculosis 6 years earlier. Chest X-ray showed a fibrocavitory lesion in the right upper lobe. A descending thoracic aortogram was carried out, which revealed neither hypertrophied bronchial arteries nor systemic collaterals. Bilateral pulmonary angiogram was normal. Selective injections of bronchial, intercostals and subclavian arteries were also normal. On selective hooking up of the right vertebral artery, an abnormal non-bronchial collateral $(2.8 \mathrm{~mm}$ in diameter $)$ was seen, which was causing hypervascularity and parenchymal blush in the left upper lobe (figure 1 and video 1). In the later phase, it demonstrated
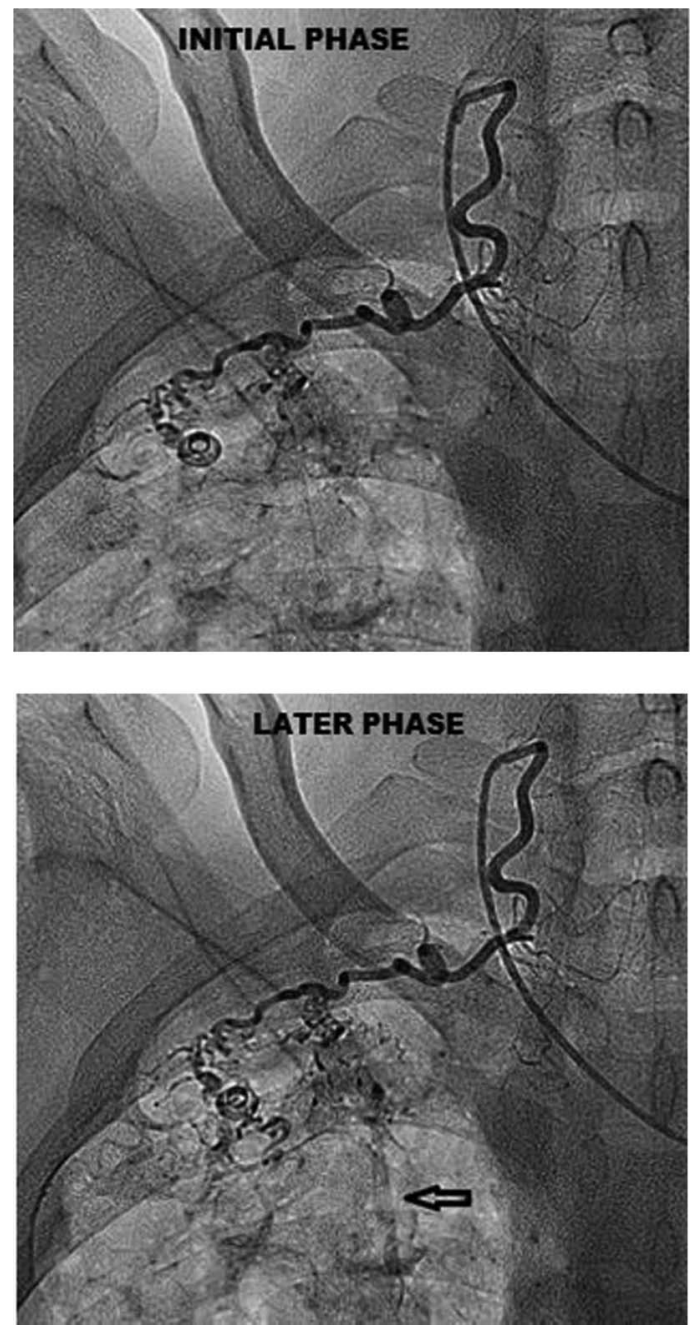

Figure 2 Selective angiogram of the right vertebral artery showing abnormal shunting from the collateral to pulmonary artery (arrow) in the later phase of angiogram. 


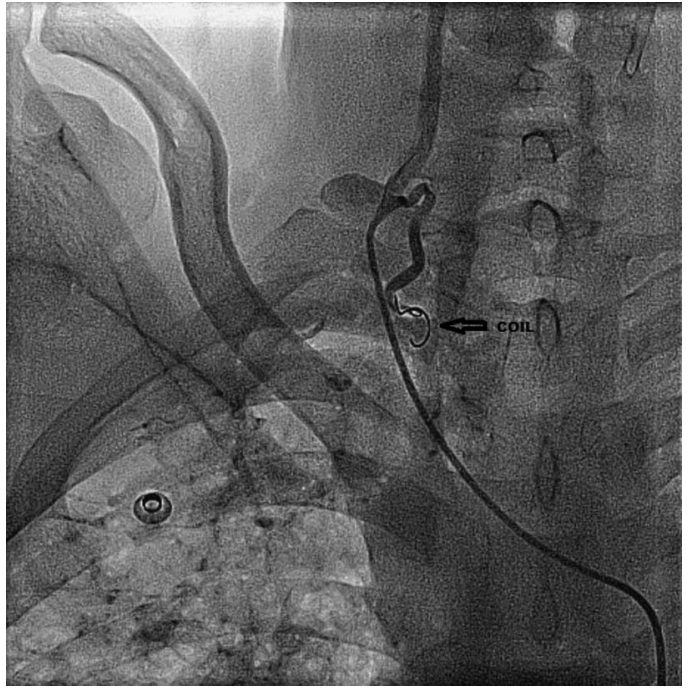

Figure 3 Postembolisation angiogram showing a metallic coil (arrow) in the proximal part of the collateral. Note that there is no flow beyond the metallic coil and no parenchymal blush is seen.

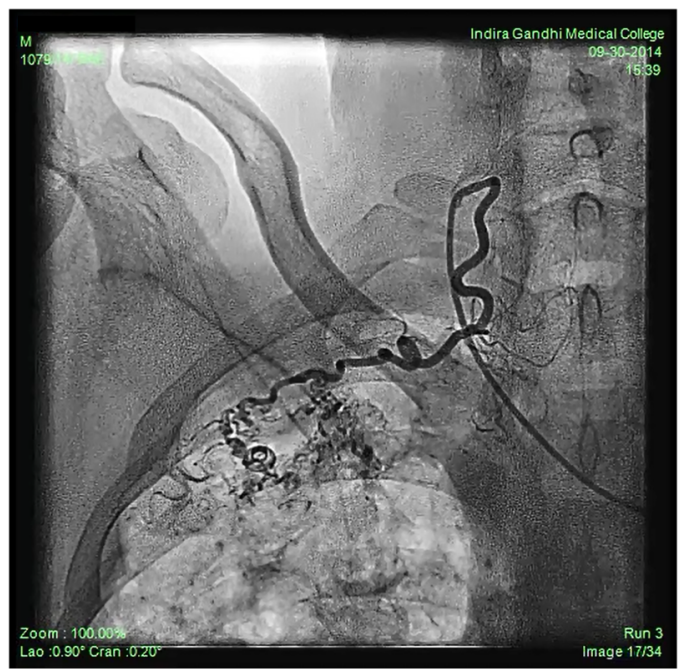

Video 2 Angiogram performed postembolisation showing no flow in the collateral, beyond the metallic coil. Note that there is no parenchymal blush in the upper lobe of the right lung.

abnormal shunting to the pulmonary artery (figure 2). We embolised this collateral vessel with a $3 \mathrm{~mm} \times 5 \mathrm{~cm}$ pushable fibred metallic coil (Cook Inc, Bloomington, Indiana, USA) via a
5 Fr Cobra catheter (figure 3). Postembolisation, the parenchymal blush disappeared (video 2). There were no procedure-related complications. The patient experienced no further episodes of haemoptysis during a follow-up period of 3 months. BAE is now considered to be the most effective nonsurgical treatment of recurrent massive haemoptysis. ${ }^{1}$ Sources of bleeding include the bronchial arteries (>90\%), pulmonary artery $(5 \%)$ and non-bronchial system collaterals $(<5 \%){ }^{2}$ Systemic sources include intercostal, thoracic, phrenic, thyrocervical, axillary, subclavian, internal mammary and vertebral arteries, as in the present case. Non-bronchial collaterals can be differentiated from the ectopic bronchial arteries, as the former never join the bronchial tree. They should be investigated and treated concurrently with the hypertrophied bronchial arteries during BAE. ${ }^{3}$ Failure to identify and treat them is the cause of early BAE failure.

\section{Learning points}

- Bronchial artery embolisation (BAE) is an efficacious non-surgical method for treatment of recurrent massive haemoptysis.

- Bronchial arteries are the most common source of bleeding in recurrent massive haemoptysis.

- Non-bronchial collaterals from systemic arteries are responsible in $<5 \%$ cases.

- Non-bronchial collaterals from vertebral arteries are extremely rare sources of recurrent massive haemoptysis.

- Failure to identify these non-bronchial collaterals may result in early BAE failure.

Competing interests None declared.

Patient consent Obtained.

Provenance and peer review Not commissioned; externally peer reviewed.

\section{REFERENCES}

1 Yoon W, Kim JK, Kim YH, et al. Bronchial and nonbronchial systemic artery embolization for life-threatening hemoptysis: a comprehensive review. Radiographics 2002;22:1395-409.

2 Hartmann IJ, Remy-Jardin M, Menchini L, et al. Ectopic origin of bronchial arteries: assessment with multidetector helical CT angiography. Eur Radiol 2007;17: 1943-53.

3 Keller FS, Rosch J, Loflin TG, et al. Nonbronchial systemic collateral arteries: significance in percutaneous embolotherapy for hemoptysis. Radiology 1987:164:687-92.

Copyright 2016 BMJ Publishing Group. All rights reserved. For permission to reuse any of this content visit

http://group.bmj.com/group/rights-licensing/permissions.

BMJ Case Report Fellows may re-use this article for personal use and teaching without any further permission.

Become a Fellow of BMJ Case Reports today and you can:

- Submit as many cases as you like

- Enjoy fast sympathetic peer review and rapid publication of accepted articles

- Access all the published articles

- Re-use any of the published material for personal use and teaching without further permission

For information on Institutional Fellowships contact consortiasales@bmjgroup.com

Visit casereports.bmj.com for more articles like this and to become a Fellow 